\title{
REVIEW
}

\section{Cost-effectiveness strategies in OSAS management: a short review}

\section{Strategie e costi/benefici nella gestione dell'OSAS}

\author{
D.M. TORALDO ${ }^{1}$, D. PASSALI ${ }^{2}$, A. SANNA ${ }^{3}$, F. DE NUCCIO ${ }^{4}$, L. CONTE ${ }^{5}$, M. DE BENEDETTO ${ }^{6}$ \\ ${ }^{1}$ Hospital Rehabilitation, Dept Cardio-Respiratory Care Unit, "V Fazzi", ASL Lecce, Italy; ${ }^{2}$ ENT Clinic, University of \\ Siena, Italy; ${ }^{3}$ Pneumology Unit, San Jacopo Hospital, Azienda USL Toscana Centro, Pistoia, Italy; ${ }^{4}$ Laboratory of \\ Human Anatomy and Neuroscience, Dept. of Biological and Environmental Sciences and Technologies, University \\ of Salento, Lecce, Italy; ${ }^{5}$ Laboratory of Interdisciplinary Research Applied to Medicine (DReAM), University of \\ Salento at the Hospital "V Fazzi", ASL Lecce, Italy; ${ }^{6}$ ENT Unit, "V. Fazzi" Hospital, ASL Lecce, Italy
}

\section{SUMMARY}

Obstructive sleep apnoea (OSAS) is an underdiagnosed chronic disease with a high prevalence in adults. It is becoming a significant social problem, since it is associated with a worsening in quality of life and increase in mortality. The cost-effectiveness ratio of diagnostic and therapeutic management of OSAS is a strategic issue to counteract the expected increasing demand of objective testing. OSAS patients with any clinical evidence of comorbidities must be studied using simplified and less expensive systems such as Home Sleep Testing (HST). On the other hand, Sleep Laboratory Polysomnography (PSG) is the gold standard to manage OSAS patients with comorbidities. It should be pointed out that the use of HST can lead to incorrect diagnosis in poorly selected OSAS subjects. This short review discusses various topics for the proper diagnosis and treatment of OSAS in view of epidemiological factors and results in terms of costs and social benefit of the disease. Whatever the strategy chosen and/or the organisational model adopted for managing OSAS, it cannot and should not take into account only cost-effectiveness. Long-term prospective studies evaluating cost-effectiveness ratios and outcomes of OSAS treatment of hospital management models versus home care models are needed.

KEY WORDS: Obstructive sleep apnoea syndrome $\bullet$ Cost-effectiveness $\bullet$ Teleservice $\bullet$ Home sleep testing $\bullet$ Polysomnography $\bullet$ Quality of Life

\section{RIASSUNTO}

L'apnea ostruttiva del sonno (OSAS) è una malattia cronica eccessivamente sotto-diagnosticata con un'alta prevalenza negli adulti. L'OSAS sta diventando un problema sociale significativo perché associata ad un peggioramento della qualità della vita ed un aumento della mortalità. Il rapporto costo-efficacia nella gestione diagnostica e terapeutica dell'OSAS è un problema strategico per contrastare la crescente domanda di test oggettivi. I pazienti OSAS che non presentano comorbilità clinicamente evidenti devono essere studiati utilizzando un sistema semplificato e poco costoso, come l'Home Sleep Testing (HST). Al contrario, la Sleep Laboratory Polisomnography (PSG) rimane il gold standard per la gestione dei pazienti con OSAS in presenza di comorbidità. Occorre sottolineare che l'uso di HST potrebbe portare ad una diagnosi errata in soggetti OSAS non ben selezionati. Questa breve rassegna si propone di offrire argomenti di riflessione sulla corretta diagnosi e trattamento dell'OSAS, in rapporto ai dati di prevalenza e alle ricadute sui costi/benefici sociali della malattia. Attualmente non può essere solo il rapporto costo/efficacia a definire il modello organizzativo adottato per la gestione dell'OSAS, in quanto si rendono necessari ulteriori studi prospettici a lungo termine, volti a validare in maniera definitiva tale rapporto nonché il confronto tra il trattamento con modelli di gestione ospedaliera versus l'assistenza domiciliare.

PAROLE CHIAVE: Sindrome delle apnee ostruttive nel sonno $\bullet$ Costi/benefici $\bullet$ Controllo medico a distanza $\bullet$ Test Ambulatoriale sul sonno $\bullet$ Polisonnografia $\bullet$ Qualità della vita

Acta Otorhinolaryngol Ital 2017;37:447-453

\section{Introduction}

OSAS is an underdiagnosed chronic disease characterised by recurrent episodes of apnoeas and hypopnoeas due to complete or partial occlusion of the upper airway during sleep ${ }^{1}$. A recent epidemiological study in adults showed that $49.7 \%$ of men and $23.4 \%$ of women have moderate to severe OSAS defined as an apnoea-hypopnoea index
$($ AHI $) \geq 15 /$ hour $^{2}$. Untreated patients are at significantly increased risk of developing cardiovascular ${ }^{34}$, metabolic ${ }^{5-7}$ and neurocognitive diseases ${ }^{8}$, as well as motor vehicle (MVAs) ${ }^{910}$ and/or work accidents ${ }^{10}{ }^{11}$. Concern that OSAS is a health issue of great relevance with having an adverse impact on the quality ${ }^{12}$ and life expectancy ${ }^{13}$ and on economic systems is growing ${ }^{14}{ }^{15}$. Furthermore, 
in Europe, it is expected that there will be an exponential increase in the number of diagnosed OSAS subjects. Two main reasons account for this: 1) the increase in OSAS prevalence in the last decades is associated with increasing prevalence and severity of obesity, the first risk factor for OSAS ${ }^{16}$; 2) in EU countries, according to the Commission directive 2014/85/EU, testing for OSAS is mandatory before granting or renewing a driver's license. Applicants or drivers with moderate or severe OSAS under treatment shall be subjected to a periodic medical review, with intervals not exceeding three years for drivers of group 1 and one year for drivers of group $2{ }^{17}$. The huge expected increase in number of diagnosis of OSAS is a challenge for health systems, leading to the need to manage OSAS and related problems by simplified tests and developing new models based on cost-effectiveness. Although a simplified and cost-effectiveness approach may help to meet the increase in number of OSAS diagnoses, it must be pointed out that the directive requires a mandatory cut-off (AHI $\geq 15$ with excessive daytime sleepiness) for OSAS testing ${ }^{18}$. It is therefore imperative, for clinical and regulatory reasons, to make a proper diagnosis and offer appropriate treatment. Objective sleep studies for OSAS may be of two types ${ }^{19-21}$ : Sleep Laboratory Polysomnography (PSG) and Home Sleep Testing (HST), the former isconsidered the diagnostic "gold standard" although highly time consuming and expensive. As a result, suspected OSAS patients may be left waiting for months before being diagnosed and able to initiate treatment. American Academy Sleep Medicine (AASM) and the American Thoracic Society (ATS) recommend the management of OSAS by HST in pre-test subjects with high OSAS suspicion without notorious morbidity or suspicion of neurological disorders, as stated in their guidelines for the use of portable monitors ${ }^{18}$. In addition, HST is considered a cost-effective alternative for OSAS diagnosis in selected patients ${ }^{22}$. Our aim is to review models based on cost-effectiveness to meet the increasing request for OSAS diagnosis and treatment. In 2016, the Italian Ministry of Health produced a document aimed to prevent and assess the clinical pathways for OSAS patients by proposing the creation of a dedicated interdisciplinary network of care ${ }^{23}$.

\section{The care of OSAS}

International statements on care of OSAS are: a) diagnosis should be confirmed by objective testing ${ }^{19} 20$; b) therapeutic choice comes from a multidisciplinary assessment ${ }^{1924}$; c) all patients should undergo long term follow-up to monitor treatment effectiveness and adherence to therapy ${ }^{19} 2025$. Developed in the early 1980's, CPAP has become established as the treatment of choice for $\mathrm{OSAS}^{26}$. It is effective as a treatment of OSAS symptoms and among all available treatments, it has the strongest evidence for a beneficial cardiovascular effect ${ }^{3}$. It has also been proven to be effective in reducing MVAs ${ }^{27}$ and to improve quality and expectancy of life ${ }^{3}$. The full-night attended sleep laboratory PSG is the gold standard for the OSAS diagnosis and for CPAP titration aimed to determine the optimal positive airway pressure 192024 . More recent studies have shown that alternatives OSAS therapies, like upper airway surgery and even oral appliances ${ }^{19}{ }^{28}$, are as effective as CPAP in mild and moderate OSAS. Indeed, although CPAP is established as a highly efficacious treatment for OSAS, its effectiveness has been limited by poor adherence ${ }^{29}$. Users may experience nasal discomfort, congestion, mask leak and claustrophobia which lead to variable levels of long term compliance ranging from $46 \%$ to $85 \%$ depending of the criteria used to define it ${ }^{30}$. It has been described a fairly linear dose response relationship such that the greater the CPAP usage, the greater the improvement in sleepiness, quality of life (QoL) and blood pressure outcomes ${ }^{31}$. As a result, there has been much research on methods to optimise CPAP adherence. Interventions that have been conducted include the verbal-visual instruction by health professionals, the application of the nasal and oral-nasal masks as well as the importance of the disease and its health effects 32 with standardised audiovisual presentations and practical demonstrations on performing standards treatments at home ${ }^{33}$. Up to now, gold standard training programs in literature have steadily improved the adherence to CPAP treatment. Many of these clinical trials ${ }^{34-36}$ with double arms (control and study) have given controversial results. These latter studies were also criticised due to the higher level of education of the control arm compared to the study arm vs. normal routine care. Consequently, results on the adherence in the study arm appeared worse. However, the majority of the experts still recommend to all patients that starting CPAP requires a high level of intensive instruction. Any educational approach, however, necessary to achieve the best possible adherence to long-term treatment, is time and money consuming.

\section{Sleep laboratory polysomnography $v s$ home sleep testing}

HST is validated for diagnosis of OSAS as well as for titration of positive airway pressure (PAP) and oral appliances (OA) devices ${ }^{19}{ }^{20}$, and auto titrating PAP (APAP) devices may be used in an unattended way to determine the therapeutic continuous PAP value ${ }^{37}$. Some studies have compared the cost-utility of different diagnostic/therapeutic strategies for the diagnosis of OSAS ${ }^{38} 39$. Pietzsch et al. ${ }^{40}$ have assessed the cost-benefit ratio by comparing the three most used diagnostic/therapeutic strategies: a) fullnight attended sleep laboratory PSG with manual CPAP titration; b) split-night PSG along with manual CPAP titration; c) HST with subsequent treatment with auto-ti- 
trating PAP (APAP). In this study, for a patient with moderate-to-severe OSAS, CPAP therapy has an incremental cost-effectiveness ratio (ICER) of $\$ 15,915$ per QALY (Quality Adjusted Life Years) gained for the lifetime horizon. Over the lifetime horizon in a population with $50 \%$ prevalence of OSAS, full-night polysomnography in conjunction with CPAP therapy is the most economically efficient strategy at any willingness-to-pay greater than $\$ 17,131$ per QALY gained, because it dominates all other strategies in comparative analysis.

In a more recent study ${ }^{41}, 191$ suspected OSAS patients were studied in advance using a pre-clinical test. More than half $(56.5 \%)$ were suspected of having OSAS. Without involvement of a sleep medicine specialist, obstructive sleep apnoea was not identified in only $5.8 \%$ of the sample. The probability to obtain an accurate diagnosis using pre-clinical tests seems not to be influenced by the presence/absence of a specialist sleep physician in accordance with the severity of the disease. The authors concluded that severe OSAS can be reliably identified with HST in a non-referred sample, irrespective of the pretest probability of the disease. Although these studies ${ }^{42}$ support, even from an economic point of view, the widespread use of the HST for OSAS diagnosis, it should be pointed out that, as reported by the American Academy of Sleep Medicine, HST may underestimate the seriousness of the hypopnoeic events compared to a full night attended sleep laboratory PSG ${ }^{43}$. This remark is not only important from a clinical and therapeutic point of view for the individual patient, but also for regulatory reasons. Indeed, as indicated by the Directive, an underestimation of the seriousness and number of apnoeas and hypopnoeas with an AHI $<15$, can result in a lack of diagnosis for an OSAS subject at risk for MVAs if the driver is not in treatment for OSAS. The AASM also remarks that HST is not indicated in case of suspected sleep related breathing disorders other than OSAS, major comorbid conditions including moderate to severe pulmonary disease, neuromuscular disease, congestive heart failure and sleep disorder. These are almost all high-prevalence diseases. Furthermore, it must pointed out some relevant limitations about HST when used in a long-term management strategy. These include: a) the need to review/reevaluate the raw data that come automatically without performing a manual analysis of the nocturnal polygraphic tracings; b) uncertainties about the long-term use of this outpatient strategy regarding the overall cost-effectiveness compared to a hospital diagnostic plan that is based on supervised polysomnography at $1^{\text {st }}$ level.

Of note, these trials for OSAS diagnosis in primary care excluded patients with comorbidities, including chronic obstructive pulmonary disease or congestive heart failure. For these latter, the concordance between HST and PSG is inadequate ${ }^{44}$, due to either poor oximetry and flow recordings in a significant number of patients ${ }^{45}$.
A randomised, controlled, non-inferiority study involved patients with OSAS who were treated with HST and compared with a specialist model (Sleep Laboratory Polysomnography) ${ }^{46}$. Among patients with OSAS, treatment under HST did not result in worse sleepiness scores and general quality of life measures, suggesting that the two treatment models may be comparable. Andreu et al. ${ }^{47}$ evaluated the efficacy of a home-based programme on clinical response, (CPAP) compliance and cost in a population of high pre-test probability of suffering (OSAS). Patients were randomised into the following three groups with no between-group differences. Group A: home respiratory polygraphy (RP) and home follow-up; Group B: hospital PSG and hospital follow-up; and Group C: home RP and hospital follow-up. Evaluation during 6 months included Epworth Sleepiness Scale (ESS), Functional Outcomes Sleep Questionnaire (FOSQ) and daily activity and symptom questionnaires. Compliance was assessed by memory cards (group A) and using an hourly counter (groups B and C). The randomised prospective study in 65 patients demonstrated that patients with a high initial probability of having OSAS can be diagnosed and treated in a home setting, with a high level of CPAP compliance and lower cost than either a hospital-based approach or home RP/hospital follow-up.

\section{Health-care providers and models of care to manage OSAS}

Different approaches and strategies have been proposed to counteract the increasing demand for access to diagnosis and therapy for OSAS ${ }^{48}$. The US created a home care model, based on HST and refundable by the insurance agencies, that deals with both diagnosis and therapeutic care of OSAS patients. This services company, called the Affordable Care Act (ACA) aims to provide high quality healthcare to OSAS patients ${ }^{49}{ }^{50}$. The ACA is gearing up towards a diagnostic model that focuses on the doctor-patient relationship. In this home care model, the company puts a network of healthcare services at the centre of this relationship, where primary care is subsequently and rapidly integrated after diagnosis. Basically, once diagnosis and the treatment are determined, the Agency rapidly provides home care technical support. Home care diagnosis and treatment is performed by health care professionals along with a consultation with a sleep specialist. This approach reduces the costs of medical staff and simplifies the delivery steps in providing therapeutic equipment at home ${ }^{51}$.

Telemedicine is a remote communication system of Information Technology IT/medical data that is used to save time and reduce costs for managing a home care service for chronic diseases ${ }^{52}$. A number of clinical studies have been carried out to evaluate the effectiveness of telemedicine interventions on adherence to CPAP treatment ${ }^{53}{ }^{54}$. 
The IT reports were transmitted and received from patient CPAP treatment home units to the reference provider centre wirelessly, and data from the study were collected and processed (Home $\leftrightarrow$ Provider). The data collected were: a) loss of pressure in the mask during sleep to CPAP treatment; b) residual AHI during CPAP treatment; c) number of hours of CPAP use. Errors in performing the treatment were easily detected from the technician, who was able to call the patients the next morning through the central Provider and resolve problems about the low efficiency of treatment. In a multicentre randomised controlled trial ${ }^{55}$, telemedicine was used to study the economic and clinical impact as well the improvement of the QoL with CPAP treatment compared to traditional follow-up with faceto-face doctor-patient controls. The 139 enrolled patients were sufficiently confident with the IT world. The quality of sleep, side effects of treatment with CPAP and QoL were evaluated at 1, 3 and 6 months. It was observed that a strategy based on telemedicine for follow-up of CPAP in patients with severe OSAS was as effective as therapy performed in hospital in accordance with the gold standard, in terms of the compliance with CPAP and improvement of symptoms, with comparable side effects and satisfaction rates. It was also found that a strategy based on telemedicine resulted in reduction of transport service and productivity costs.

PREDICT, a multicentre randomised controlled study ${ }^{56}$, used the telemedicine to assess the clinical and economic aspects of CPAP treatment in OSAS patients older than 65 years. It was found that CPAP treatment reduced subjective and objective sleepiness to that observed in younger patients. Secondary goals were to determine CPAP clinical efficacy, cost-effectiveness ratio and real usefulness of treatment (model-based cost-effectiveness analysis) compared to alternative treatments with APAP/Bilevel/C FLEX (BSC). The QoL at 12 months of treatment was measured by the European Quality of Life-5 Dimensions (EQ-5D). In elderly patients with OSAS, CPAP treatment reduced somnolence more significantly compared to treatment with APAP/Bi-Level/C FLEX (BSC) over a period of 12 months, improving the EQ-5D. Although IT telemonitoring systems saved operating costs and managed several patients simultaneously (at least 100), by using a single provider they hinted at possible medico-legal disputes ${ }^{57}$. First of all, there is no international standard of care for telemedicine ${ }^{58}$. Standards of care exist only for services for the individual, but there are still not many e-Health practices. Medico-legal issues are: a) respect for personal privacy, b) inaccuracies of self-reporting of patients in data recording, c) the resolution limits of data to be recorded and consequent delays due to failure/delayed treatment after recording of data, $d$ ) failure of systems that do not work correctly.

In the US, there is a national society in telemedicine called TelaDoc ${ }^{59}$ that features a American National Committee to guarantee certification of electronic systems used in tel-

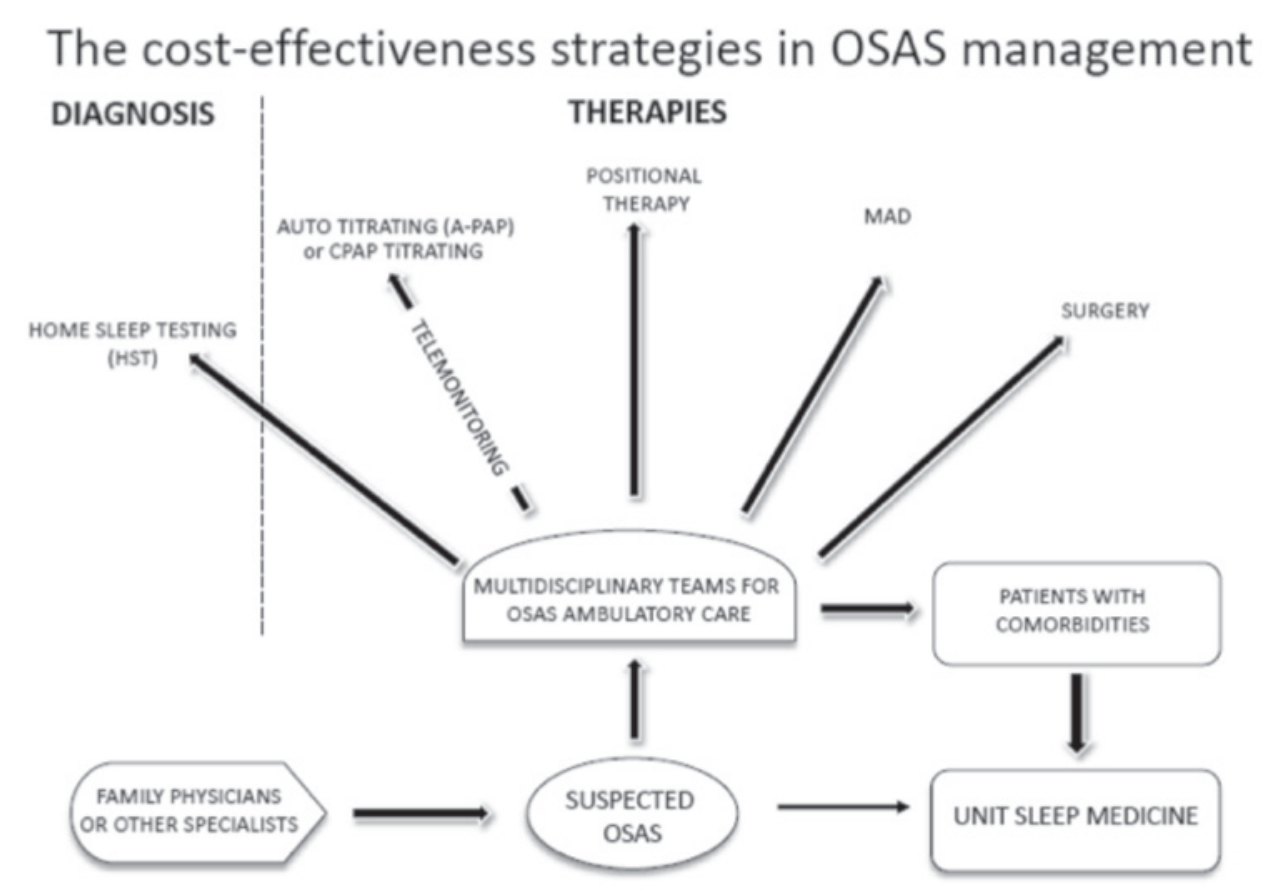

Fig. 1. Model of OSAS management resulting from cost-effectiveness strategies. 
emedicine, along with the production of evidence-based clinical practice guidelines for registering data quality ${ }^{60}$. There are emerging results in the literature that support the role of non-medical health professionals who are expert in sleep study, such as nurses, caregivers and IT/ health care, who are able to manage home care OSAS in a cost-effective way. We still need more long-term prospective studies that can evaluate the cost-effectiveness ratio, including direct and indirect costs of hospital management models versus models that take into account new, qualified non-medical personnel care.

Another randomised, prospective, controlled study included OSAS patients who underwent CPAP treatment and HST during follow-up. The primary outcome was CPAP compliance at 6 months. Secondary outcomes were ESS score, EuroQoL, patient satisfaction, body mass index (BMI), blood pressure and cost-effectiveness. For patients with OSAS, the treatment provided did not result in worse CPAP compliance compared with a specialist model (Sleep Center Polysomnography) and was shown to be a cost-effective alternative ${ }^{61}$.

\section{Conclusions}

The huge expected increase in the prevalence and incidence of OSAS is a challenge for healthcare systems. The model of OSAS management resulting from costeffectiveness strategies is shown in Figure 1. Healthcare systems must ensure rapid access to diagnosis and treatment for each individual with suspected OSAS and avoid exposure to the risk of MVAs and work accidents for both OSAS subjects and others involved in accidents caused by OSAS subjects. HST, health-care providers and the proposed model aimed to manage OSAS are a possible effective response to counteract the increasing demand for access to diagnosis and therapy for OSAS. It takes priority to involve non-medical healthcare professionals and create training courses for all health workers on the management of OSAS and OSAS-related problems. Whatever the strategy chosen and/or organisational model adopted for managing OSAS, it cannot and should not take into account only cost-effectiveness. Long-term prospective studies aimed at evaluating the cost-effectiveness ratio, accuracy of diagnosis and outcomes of OSAS treatment of hospital management models versus home care models are needed.

\section{References}

1 White DP. Pathophysiology of obstructive sleep apnoea. Thorax 1995;50:797-804.

2 Heinzer R, Vat S, Marques-Vidal P, et al. Prevalence of sleep-disordered breathing in the general population: the HypnoLaus study. Lancet Respir Med 2015;3:310-8.

3 Marin JM, Carrizo SJ, Vicente E, et al. Long-term cardiovascular outcomes in men with obstructive sleep apnoea- hypopnoea with or without treatment with continuous positive airway pressure: an observational study. Lancet 2005;365:1046-53.

4 Yaggi HK, Concato J, Kernan WN, et al. Obstructive sleep apnea as a risk factor for stroke and death. N Engl J Med 2005;353:2034-41.

5 Toraldo DM, DE Nuccio F, DE Benedetto M, et al. Obstructive sleep apnoea syndrome: a new paradigm by chronic nocturnal intermittent hypoxia and sleep disruption. Acta Otorhinolaryngol Ital 2015;35:69-74.

6 Passàli D, Tatti P, Toraldo M, et al. OSAS and metabolic diseases. Round Table, 99 ${ }^{\text {th }}$ SIO National Congress, Bari 2012. Acta Otorhinolaryngol Ital 2014;34:158-66.

7 Kendzerska T, Gershon AS, Hawker G, et al. Obstructive sleep apnea and incident diabetes. A historical cohort study. Am J Respir Crit Care Med 2014;190:218-25.

8 Peppard PE, Szklo-Coxe M, Hla KM, et al. Longitudinal association of sleep-related breathing disorder and depression. Arch Intern Med 2006;166:1709-15.

9 Sanna A. Obstructive sleep apnoea, motor vehicle accidents, and work performance. Chron Respir Dis 2013;10:29-33.

10 Garbarino S, Pitidis A, Giustini M, et al. Motor vehicle accidents and obstructive sleep apnea syndrome: a methodology to calculate the related burden of injuries. Chron Respir Dis 2015;12:320-8.

11 Garbarino S, Guglielmi O, Sanna A, et al. Risk of occupational accidents in workers with obstructive sleep apnea: systematic review and meta-analysis. Sleep 2016;39:1211-8.

12 Garbarino S, Lanteri P, Durando P, et al. Co-morbidity, mortality, quality of life and the healthcare/welfare/social costs of disordered sleep: a rapid review. Int J Environ Res Public Health 2016;13(8). pii: E831. doi: 10.3390/ijerph13080831.

13 Punjabi NM, Caffo BS, Goodwin JL, et al. Sleep-disordered breathing and mortality: a prospective cohort study. PLoS Med 2009;6:e1000132.

14 Jennum P, Kjellberg J. Health, social and economical consequences of sleep-disordered breathing: a controlled national study. Thorax 2011;66:560-6.

15 Leger D, Bayon V, Laaban JP, et al. Impact of sleep apnea on economics. Sleep Med Rev 2012;16:455-62.

16 Garvey WT, Mechanick JI, Brett EM, et al. American association of clinical endocrinologists and american college of endocrinology comprehensive clinical practice guidelines for medical care of patients with obesity. Endocr Pract 2016;22:1-203.

17 Bonsignore MR, Randerath W, Riha R, et al. New rules on driver licensing for patients with obstructive sleep apnoea: EU Directive 2014/85/EU. Eur Respir J 2016;47:39-41.

18 Kuna ST, Badr MS, Kimoff RJ, et al. An official ATS/AASM/ ACCP/ERS workshop report: Research priorities in ambulatory management of adults with obstructive sleep apnea. Proc Am Thorac Soc 2011;8:1-16.

19 Epstein LJ, Kristo D, Strollo PJ, et al. Clinical guideline for the evaluation, management and long-term care of obstructive sleep apnea in adults. J Clin Sleep Med 2009;5:263-76.

20 Sanna A, Bellofiore S, Di Michele L, et al. Indicazioni per la diagnosi e cura della sindrome delle apnee ostruttive del sonno nell'adulto. Documento dell'Associazione Scientifica 
Interdisciplinare per lo studio delle Malattie Respiratorie (AIMAR). www.aimarnet.it. Last access 14 November 2016.

21 Passali D, Caruso G, Arigliano LC, et al. Database application for patients with obstructive sleep apnoea syndrome. Acta Otorhinolaryngol Ital 2012;32:252-5.

22 Mansfield DR, Antic NA, McEvoy RD. How to assess, diagnose, refer and treat adult obstructive sleep apnoea: a commentary on the choices. Med J Aust 2013;199.

23 Italian Ministery of Health. Documento di Indirizzo: Sindrome Apnee Ostruttive nel Sonno (OSAS): quale prevenzione possibile. In press. Rome, Febr 2016.

24 Durán-Cantolla J, Zamora Almeida G, Vegas Diaz de Guereñu $\mathrm{O}$, et al. Validation of a new domiciliary diagnosis device for automatic diagnosis of patients with clinical suspicion of OSA. Respirology 2017;22:378-85.

25 Aurora RN, Collop NA, Jacobowitz O, et al. Quality measures for the care of adult patients with obstructive sleep apnea. J Clin Sleep Med 2015;11:357-83.

26 Malhotra A, Orr JE, Owens RL. On the cutting edge of obstructive sleep apnoea: where next? Lancet Respir Med 2015;3:397-403.

27 George CF. Reduction in motor vehicle collisions following treatment of sleep apnoea with nasal CPAP. Thorax 2001;56:508-12.

28 Ramar K, Dort LC, Katz SG, et al. Clinical practice guideline for the treatment of obstructive sleep apnea and snoring with oral appliance therapy: an update for 2015. J Clin Sleep Med 2015;11:773-827.

29 Jean Wiese H, Boethel C, Phillips B, et al. CPAP compliance: video education may help! Sleep Med 200;6:171-4.

30 Wozniak DR, Lasserson TJ, Smith I. Educational, supportive and behavioural interventions to improve usage of continuous positive airway pressure machines in adults with obstructive sleep apnoea. Cochrane Dtabase Syst Rev 2014:CD007736.

31 Salvaggio A, Lo Bue A, Isidoro SI, et al. Gel pillow designed specifically for obstructive sleep apnea treatment with continuous positive airway pressure. J Bras Pneumol 2016;42:362-36.

32 Lettieri CJ, Walter RJ. Impact of group education on continuous positive airway pressure adherence. J Clin Sleep Med 2013;9:537-41.

33 Lai AYK, Fong DYT, Lam JCM, et al. The efficacy of a brief motivational enhancement education program on CPAP adherence in OSA: a randomized controlled trial. Chest 2014;146:600-10.

34 Smith I, Nadig V, Lasserson TJ. Educational, supportive and behavioural interventions to improve usage of continuous positive airway pressure machines for adults with obstructive sleep apnoea. Cochrane Database Syst Rev 2009:CD007736.

35 Haniffa M, Lasserson TJ, Smith I. Interventions to improve compliance with continuous positive airway pressure for obstructive sleep apnoea. Cochrane Database Syst Rev 2004:CD003531.

36 Sedkaoui K, Leseux L, Pontier S, et al. Efficiency of a phone coaching program on adherence to continuous positive airway pressure in sleep apnea hypopnea syndrome: a randomized trial. BMC Pulm Med 2015;15:102.
37 Kapoor M, Greenough G. Home sleep tests for obstructive sleep apnea (OSA). J Am Board Fam Med 2015;28:504-9.

38 Billings ME, Kapur VK. Medicare long-term CPAP coverage policy: a cost-utility analysis. J Clin Sleep Med 2013;9:1023-9.

39 Weatherly HLA, Griffin SC, Mc Daid C, et al. An economic analysis of continuous positive airway pressure for the treatment of obstructive sleep apnea-hypopnea syndrome. Int $\mathrm{J}$ Technol Assess Health Care 2009;25:26-34.

40 Pietzsch JB, Garner A, Cipriano LE, et al. An integrated health-economic analysis of diagnostic and therapeutic strategies in the treatment of moderate-to-severe obstructive sleep apnea. Sleep 2011;34:695-709.

${ }^{41}$ Aurora RN, Putcha N, Swartz R, et al. Agreement between results of home sleep testing for obstructive sleep apnea with and without a sleep specialist. Am J Med 2016;129:725-30.

42 Collop NA, Anderson WM, Boehlecke B, et al; Portable Monitoring Task Force of the American Academy of Sleep Medicine. Clinical guidelines for the use of unattended portable monitors in the diagnosis of obstructive sleep apnea in adult patients. J Clin Sleep Med 2007;3:737-47.

43 Cooksey JA, Balachandran JS. Portable monitoring for the diagnosis of obstructive sleep apnea. Chest 2015;149:1074-81.

${ }_{44}$ Oliveira MG, Nery LE, Santos-Silva R, et al. Is portable monitoring accurate in the diagnosis of obstructive sleep apnea syndrome in chronic pulmonary obstructive disease? Sleep Med 2012;13:1033-8.

45 Suárez M, Osorio J, Torres M, et al. Should the diagnosis and management of OSA move into general practice? Breathe 2016;12:243-7.

46 Chai-Coetzer CL, Antic NA, Rowland LS, et al. Primary care vs specialist sleep center management of obstructive sleep apnea and daytime sleepiness and quality of life: a randomized trial. JAMA 2013;309:997-1004.

47 Andreu AL, Chiner E, Sancho-Chust JN, et al. Effect of an ambulatory diagnostic and treatment programme in patients with sleep apnoea. Eur Respir J 2012;39:305-12.

48 Chai-Coetzer CL, Antic NA, McEvoy RD. Ambulatory models of care for obstructive sleep apnoea: diagnosis and management. Respirology 2013;18:605-15.

49 Glied S, Solís-Román C, Parikh S. How the ACA's health insurance expansions have affected out-of-pocket cost-sharing and spending on premiums. Issue Brief (Commonw Fund) 2016;28:1-16.

50 Riggs KR, Buttorff C, Alexander GC. Impact of out-of-pocket spending caps on financial burden of those with group health insurance. J Gen Intern Med 2015;30:683-8.

51 Moro M, Westover MB, Kelly J, et al. Decision modeling in sleep apnea: the critical roles of pretest probability, cost of untreated obstructive sleep apnea, and time horizon. J Clin Sleep Med 2016;12:409-18.

52 Hwang D. Monitoring progress and adherence with positive airway pressure therapy for obstructive sleep apnea: the roles of telemedicine and mobile health applications. Sleep Med Clin 2016;11:161-71.

53 Isetta V, León C, Torres M, et al. Telemedicine-based approach for obstructive sleep apnea management: building evidence. Interact J Med Res 2014;3:e6. 
54 Isetta V, Negrín MA, Monasterio C, et al. A Bayesian costeffectiveness analysis of a telemedicine-based strategy for the management of sleep apnoea: a multicentre randomised controlled trial. Thorax 2015;70:1054-61.

55 Fox N, Hirsch-Allen AJ, Goodfellow E, et al. The impact of a telemedicine monitoring system on positive airway pressure adherence in patients with obstructive sleep apnea: a randomized controlled trial. Sleep 2012;35:477-81.

56 McMillan A, Bratton DJ, Faria R, et al. A multicentre randomised controlled trial and economic evaluation of continuous positive airway pressure for the treatment of obstructive sleep apnoea syndrome in older people: PREDICT. Health Technol Assess 2015;19:1-188.

57 McDaid C, Griffin S, Weatherly H, et al. Continuous positive airway pressure devices for the treatment of obstructive sleep apnoea-hypopnoea syndrome: a systematic review and economic analysis. Health Technol Assess 2009;13:143-274.
58 Gallegos A. Frontline Medical News. Telemedicine poses novel legal risks for doctors. Featur Top Chest online Oct 6 2015.

59 Uscher-Pines L, Mehrotra A. Analysis of Teladoc use seems to indicate expanded access to care for patients without prior connection to a provider. Health Aff (Millwood) 2014;33:258-64.

${ }^{60}$ Uscher-Pines L, Mulcahy A, Cowling D, et al. Access and quality of care in direct-to-consumer telemedicine. Telemed J E Health 2016;22:282-7.

61 Sanchez-de-la-Torre M, Nadal N, Cortijo A, et al. Role of primary care in the follow-up of patients with obstructive sleep apnoea undergoing CPAP treatment: a randomised controlled trial. Thorax 2015;70:346-52.

Received: November 30, 2016 - Accepted: March 11, 2017 